\title{
Strategic Development of Innovative Social Services in Elbasan
}

\section{Denisa Ballhysa}

\author{
Lecturer, Department of Social Sciences, Faculty of Education, "Aleksander Xhuvani" University
}

Elbasan, Albania; denisa.ballhysa@uniel.edu.al

\section{Doi:10.5901/ajis.2016.v5n3s1p52}

\begin{abstract}
Modern times has brought major changes to the conceptual social life. Even the dimensions to be assessed not only sociologically and conceptually, but also to consider more joint efforts of the state, society and family. Especially for building social rights policies, integrated by improving the structure of social relations. This should be the essence of each regional social policy, local way of organizing community life. In terms of decentralization of social services, integration services are indications that local authorities should assess not only to root "society board" but target the most vulnerable groups. Rendered necessary by the implementation of a community instruments of the most innovative social policies being considered as trace methodological work and how to move forward strand of improving: Social Plan Area. In this case its implementation will affect the strategic development of innovative social services to improve and provide more social services integrated with health not only for the city but also in Elbasan Municipality Paper, Labino -Fushe, Tregan, Shirgjan, Shushicë, to meet local policies for economic, social and cultural, creating social integration of health services, a calendar of activities for the implementation of the priorities in the field of social protection, to a common vision on the delivery of services
\end{abstract}

Keywords: decentralization; social policy; network, integration of social - health services.

\section{Introduction}

In Albania, in the period after the collapse of the dictatorial regime until today is visible an improvement of the living conditions at the national level as well as at the Regional. In terms of-m measurability, different pace of development and the character of his somewhat spontaneous, make this improvement is relative: positive changes in some urban areas are vigorous and highly visible, while a large part of the rural areas lag behind dramatically and in many components of development.

The study "Social Area Plan" intends to present before the concerned institutions and agencies involved in social development, a modern approach to social development orientation of the area.

In terms of methodology, this study is an integrated treatise on these issues and is based on a preliminary analysis work. The study brings attention once again on the phenomenon of social exclusion. Social exclusion in Albania is a byproduct of several factors. A very low level economic mis-governance, slowness in the process of decentralization, insufficient policies of the social inefficiency in targeting poor families, insufficient implementation of laws and regulations in force are some of the elements that favor or promote social exclusion. Differences in lifestyle and benefits of options between residents of rural and urban, mountainous and lowland between target social groups and the rest of the population have turned into gaps that feed exclusion social. Details of previous studies and relevant policy documents highlight how social groups in difficulty, children of families in need, persons with disabilities, the unemployed, the elderly and members of the Roma and Egyptian communities.

"The social area plan" devotes considerable attention to these target groups. Concentration of economic level, poverty is inevitable focus of any study of the nature of a long-term programming. The lack of a universal acceptance on a measurement of poverty indicators and risks always lead to inaccuracy or lack reliability of certain monitoring applications later in inadequate interventions and effective. The study recognizes, acknowledges and highlights the need for a stable system and better coordinate the monitoring, which in the current situation poses a real challenge for the design and implementation of social policies in Albania. The current stage of research and experience accumulated by successful projects or not, raise the need for a re-conceptualization of social services. It has become essential that access to the construction and delivery of social services to be an integrated and comprehensive approach. In this regard, the decentralization of social services suggested as a solution, which through added flexibility would create preconditions for comprehensive policies and interventions. Also, there are good reasons to explore the possibilities for the realization of social networks, resulting in an integrated approach to social services. 
Clearly, in the context of an overall strategy, social services have much to offer in terms of reducing poverty and improving the lives of poor and vulnerable. Local governments, suggested in the study, are more suited to handle several functions related to the provision of social programs. They have already been made aware of this crucial role and functions are realized through the provision of some part of good service. It is very important to examine in detail the ways in which de facto local authorities can maximize and expand the involvement of the above mentioned, focusing on improving the performance and measurability of outcomes of services provided. "Social area plan" offers a comprehensive new approach to the strategic planning. Strategic planning is a discipline born in the private sector, of which contaminated many public administrations essentially consists in "considering the current situation and future development of an" organization or a community, to set goals, develop a strategy for achieving and measuring results "(Osborne, Gaebler, 1995, 291). Various processes of strategic planning using different ways, but they all follow some basic steps (...). Unlike the private sector, public administration is needed is an additional element: consensus.

One of the advantages of consensus on a long-term strategic vision is to address drainage potential energies towards common development objectives. By David Osborne and Ted Gaebler Strategic planning is not something you do from time to time, to develop a plan, but it is orderly, linear. "An important element is not the plan, but planning. Creating a consensus on a vision for the future, an" organization or a community gives its members a "road idea who wish to pursue." This allows everyone - not just the leaders, to understand who is the way to be taken, helping them to seize unexpected opportunities and cope with unexpected problems, without waiting for orders from above. (Id, p.292).

Long-term strategic planning, according to many authors (Tanese, 2006) is one of the most important innovations in urban and territorial governance shown in the last twenty years. Social Area Plan is an instrument of strategic planning designed to build integrated system of social services. Lavinia Bifulco and Ota de Leonardis suspicious about the changes on the horizon in the field of social, claim policy of integration processes between policies on social issues are another important point of observation.

Driven from Europe, and closely related to the location, the integration of social services is configured as a strategy to pursue common objectives with different policies, for example, to build or rebuild services for care social policies related to health, employment, social protection, local development trying to combine with each other and, in turn, be combined into a common area.

These convergences encourage various combinations of reports, information and to redefine the subjects and competencies to create forms of cooperation, agreement and real integration between the different actors. This happens as operational practices on the ground, and intervention agencies, as in the technical and administrative management of elections, both in institutional responsibility, political and administrative (Biflulco, De Leonardis, 2006).

Some authors (Donolo 2005, Martelli, 2007) evidence, in addition to the potential for transformation, the risks associated with "ritualism" by which local governments are approaching the new instruments of planning, social area plan, Strategic Planning, the Local Development by defining them as a further fulfillment to realize. Adding protocols, act local agreements that characterize the planning processes of social services threaten to resemble mystical organizations that promote ritualistic practices in a vicious cycle. This risk may be submitted and social area plan.

They decide on the system in the form of integrated social services all operating in a specific territory. Various public entities and private companies that are carriers of values, objectives, different missions that are expected to work together to assist their citizens. Social Area Plans constitute the vehicle through which a task can be accomplished and effective integrated social-health.

Social Area Plan should not be considered a single rigid instrument to a particular territory. Rather he must continually adapted to the context in which put into operation by expanding the objectives and implementation territorial space, being considered as methodological trail threading work and how to move forward and improve. Gets, so, great importance joint construction and the creation of an overview and integrated problems that face. Not only in terms of cooperation and integration, but also in a broader context must be aware more and more on the fact that there may be faced with the seriousness of the problems separately. For this reason it is imperative that all energies available in the territory to work together.

In case this capacity is expected to affect the strategic development of innovative to improve social services and to provide more social services integrated with those of health not only in the city of Elbasan, but also in the municipalities Paper, Labinot-Fushe, Tregan, Shirgjan, Shushicë. The social area plan in the design of an integrated social system (Battistella, De Ambrogio, Ranci Ortigosa, 2007, p. 28-29) must identify:

The objectives, priorities, instruments and tools;

- Organization of services, resources and quality requirements;

- $\quad$ Disclosure of data within the system information / statistics; 
- $\quad$ Procedures to ensure integration of services and benefits;

- Format of consultation between Local Health Units or forms of cooperation with non-profit social service providers;

- Coordination with state authorities peripheral;

- Cooperation between local services, society and the local community.

\section{What Will Serve New Social Area Plan?}

On completion of local economic development policies and social-cultural development of Elbasan Municipality, municipalities Papër, Labinot-Fushe, Tregan, Shirgjan, Shushicë; As a calendar of activities in these areas for the implementation of priorities in the field of social protection of the rights of children, women, persons with disabilities, ethnic groups and the elderly as well as the support of families and individuals at risk of social exclusion ${ }^{1}$;

A common vision for the provision of social-helthy integrated services.

This plan aims to:

- Analyze the social and economic situation of social groups most vulnerable to poverty and social exclusion in the municipalities Paper, Labinot-Fushe, Tregan, Shirgjan, Shushicë considering best practice Social Area Plan of Elbasan Municipality;

- Identify the causes of the situation;

- $\quad$ Propose interference with social and economic nature to improve the situation;

- To require planning and interactions between institutions regarding the need for financial and human resources to meet the costs arising;

- To describe and make available best practices in terms of management based Inter social and health services;

- As a basis for building projects and social policies following².

Social area plan should contain general principles such as subsidiarity, cooperation, efficiency and effectiveness, financial coverage, continuity. It is responsible for the participation of all components of the public, not closely related to the local community in its development processes. Its implementation consists of several phases over methodological (Battistella, De Ambrogio, Ranci Ortigosa, 2007):

- Ensure participation of all stakeholders (local government, non-profit organizations, civil society, community);

- Reconstruction of the "knowledge base", which is useful for analyzing needs and existing knowledge;

- Identification of strategic objectives;

- Clarity of content;

- Approval of the plan of the area and the signing of a "framework agreement".

The process should not be confused with typical administrative intervention, but should include among their combined actions, empowerment, counseling, communication involving all parties able to provide input at various stages of implementing the social area plan.

Interactions between the stakeholders should be based on the needs and opportunities for a specific territory in order to realize social-helthy services for the community. Special attention should be given to the technical and methodological conditions, necessary for the evaluation of the design and implementation of the social area plan, to the responsibilities of participating of the actors, and its management functions, deciding the functions of the governance in a cycle virtuoso.

\footnotetext{
${ }^{1}$ This plan is related to: the general development plan of the city of Elbasan and municipalities Papër, Labinot-Fushe, Tregan, Shirgjan, Shushicë; Creating a new management of innovative social inter-health services; Protection of the rights of the most vulnerable groups of society; Implementation of local action plans in relevant areas.

2 For the preparation of this material was kept in consideration: the National Strategy for Children, Disability, Gender Equality, Community Rom; National Strategy 2007-2013 social services sector; Coordination of national policies of Elbasan Municipality, municipalities Papër, Labinot-Fushe, Tregan, Shirgjan, Shushicë; Increased attention on issues of social protection; Social Area Plan, Elbasan, 2005, 2009.
} 


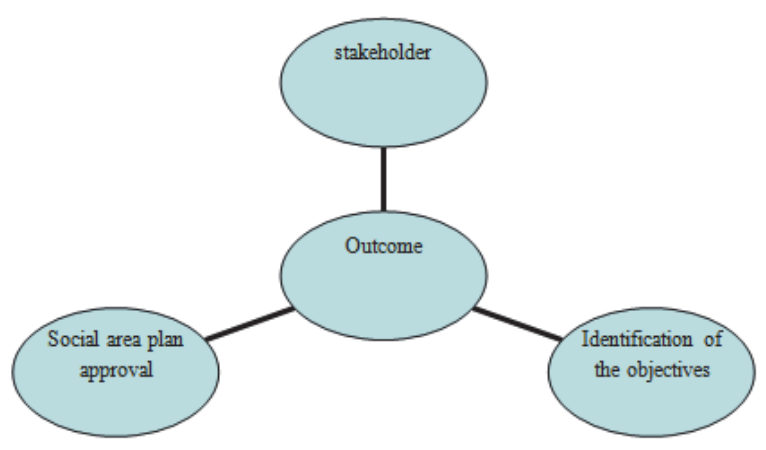

\section{General Conclusion}

Albania in general and the area under consideration in this study are undergoing social transformation in multiple directions. One part of transformation (and some of the problems) are the universal nature, phenomena known and accepted, a part of which developed countries have undergone stages of the historical development and the other part of the experience now even global nature phenomena. Like any transformation, they do not exceed the quietly and without social impacts, which call for intervention if the legislation and enforcement legislation, as well as through projects that aim to minimize the trauma and make safer and healthier future individual. In the case of Albania, the difficulties created by these transformations are even bigger, has a historical component and a cultural component that other things are inevitably. Over 20 years experience of social and interventions made by state and governmental agencies there is place for optimism. Not all interventions have been counterproductive and a good part of the investments have given a result.

A carefully observed experience and bitter lessons learned or not the recent past by always constitute a sound basis for strategy enough. "Social area plan "seeks to respond to the extraordinary dynamism of social development, which is not only rapid, but often spontaneous, to minimize major problems arising not only of the past, but as by- product developments.

The study initiated by the idea and supported it that the efficiency of interventions in the social sector in the near future can be effective and result in minimal cost only if access to the social problems of the area is an integrated approach, comprehensive, multi-stakeholder officials and voluntary self-motivated, flexible and coordinated. More coordination and more real decentralization in local governments in providing social services will bring faster results, lower cost compared to the benefits of social interventions; more sustainable results long-term perspective and above all an awareness of all the actors to be more involved. Data analysis and project files are an example that illustrates this approach. One of the most important directions of intervention is social protection for those in need. Traditional institutions of politics, education, and culture should be more aware of the urgency of such a priority. In particular, the focus should be to establish and scope of community social service institutions coupled with appropriate improvements in typology, physiognomy and social functions of the respective institutions. Now community service institutions are the sole responsibility of local government. At the same time they continue to have an irreplaceable role in building a society of healthy, fair, free of discrimination against and social inequality suffering individuals define the status of man in need and who are becoming more numerous in number in our society. The rapid transformations make the most immediate and significant role of community service institutions. Community social services should not functioning in a sporadic, spontaneous and fragmented process. The experience showed that such a thing does not bring lasting results. Create a network as broad and adequate social services community with a more integrated approach to social care provided by agencies of local government becomes a necessity to meet people's needs and demands of marginalized groups, or with problems and specific social needs. An integrated approach and support of a network of such results should be the subject of any regional or local social policy. Traditionally, community social policies are measured and evaluated with the construction and operation of institutions of social life in certain territories. Such a rating system is inevitably fragmented and a "process than zero". Care provided to persons in need and supported with complementary care to state agencies, local government and other non-profit or civil society should be measured and evaluated as an integral part of the local social and community policies.

Programming of social policy developments appear as a decentralization of planning application.

In this logic-governing conditions for collaboration between actors (institutional or not) that can be developed in a 
profitable way and why, through interaction, they can develop a collective learning process.

Various improvements are participating democracy supporters believe in the realization of the social area plan:

- $\quad$ enhancing of civic culture by making participants better citizens, more conscious, active and confident in their abilities, skipping the traditional democratic channels;

- The promotion of mutual respect, being a school of democracy that develops skills and competencies of those participating;

- They produce more effective decisions, often taking advantage of the deep knowledge of the problems people have and their proposals for solutions;

- To enable the achievement of mutual solutions to problems without affecting the system of values;

- Increase the legitimacy of decisions; through procedures involving stakeholders, the decision is implemented by the government follow-up system;

- To increase the chances of success in implementing policies, thanks to the involvement of stakeholders present in a territory;

- Positively affect the reaction and effectiveness of the administrative apparatus: will be able to generate the increase of social relationships capital available in a given territory;.

Decentralization of social services makes more visible and public responsibility to take local government. Therefore appears necessary processing new policy community care, enhance the role of special regional institutions and local social service. Such processes must go on study stages, stages of research undertaken by social scientists and implementing institutions or providers of these services.Although necessary, the stage that is social services in Albania, these studies are lacking. Reforming the social system aims already ended and that the process of decentralization of social service institutions are generally under the responsibility of local government and civil society. This is a big step of decentralization that already has all the conditions to become a reality.

\section{References}

Bagnasco A., Le Gales P., (2001), Le Città Europee Come Società E Come Attori, In Bagnasco E Le Galès (a cura di), Le Città Nell'europa Contemporanea, Napoli, Liguori, 2001, 1-45.

Balducci (1998), Costruire il futuro, II Mulino.

Battistella A., De Ambrogio U., Ranci Ortigosa E., (2007), II Piano di Zona. Costruzione, gestione, valutazione, Carocci Faber, Roma.

Bifulco L, De Leonardis O.,(2006), Integrazione tra le politiche come opportunità politica, Materiali Dispense Università Cattolica di Milano.

Dente B., Melloni E. (2005), Cap.1 II Piano Strategico come strumento di governance locale, In: Associazione Torino Internazionale, Scenari Per II Sistema Locale, Valutazione sul Piano Strategico di Torino e sulle prospettive di sviluppo dell'area metropolitana.

Donolo C. (2005), "Dalle politiche pubbliche alle pratiche sociali nella produzione di beni pubblici? Osservazioni su una nuova generazione di policies", in Stato e Mercato, 33-65.

Gaebler D, Osborne T (1995), Dirigere e governare, Garzanti.

Leone L., Prezza M. (1999), Costruire e valutare i progetti nel sociale, Franco Angeli, Milano.

Martelli A. (2007) 3.2.4. Programmazione locale e piani di zona, Verso una nuova governance locale delle politiche sociali? ALSS II Mulino 1, 97-108.

Tanese A., Di Filippo E., Renne R. (a cura di) (2006), La pianificazione strategica per lo sviluppo dei territori. Analisi e strumenti per I"innovazione, Dipartimento FunzionePubblica, Rubbettino Ed.

Palumbo M. (2005), La valutazione sociale. Un excursus tra teoria e percorsi attuativi incerti, La Rivista delle Politiche Sociali, 2, 2005 Roma, Ediesse.

Perulli P. (2006), Governare strategicamente, RPS Rivista Politiche Sociali, 219-233.

Siza R. (2000), Piani e progetti nella programmazione sociale, In: Pianeta infanzia, Quaderni del Centro nazionale di documentazione e analisi per l'infanzia e adolescenza, n.15, Firenze.

Tanese A., Di Filippo E., Renne R. (a cura di) (2006), La pianificazione strategica per lo sviluppo dei territori. Analisi e strumenti per I"innovazione, Dipartimento FunzionePubblica, Rubbettino Ed. 